\title{
CONSERVATION IN ACTION
}

By FRED G. BARD, Director, Provincial Museum

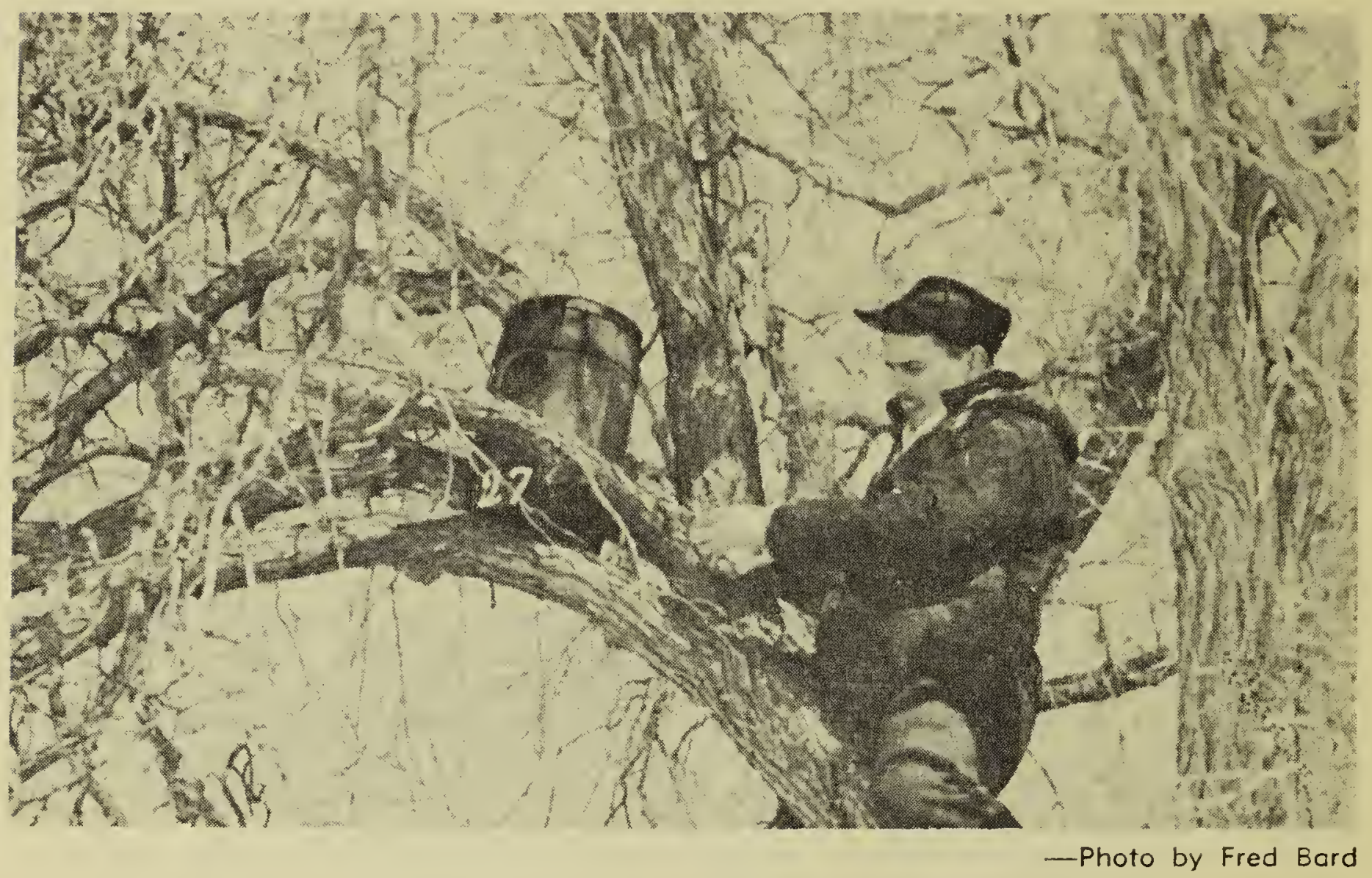

Dalton Dean, Museum Assistant.

Two years ago the Museum carried on some experiments that were later published in the "Blue Jay." These experiments were to solve the housing problems for Golden-eye Ducks, mainly along the Qu'Appelle Valley.

The lack of nesting sites caused through the long period of drought has been somewhat overcome by the placing of small nail kegs painted in camouflage colours and given numbers for later checking. These barrels have been used by Goldeneye Ducks as well as a female Red Squirrel who used one for two years to raise her young and a Sparrow Hawk.

In order to obtain sufficient data, a program was launched this last winter, through the Wildlife Conservation League - a junior organization of teen-age boys. The instruction comes from $\mathrm{Mr}$. Al Copeman, the founder of the League, Mr. Hartwell of the Natural Resources and other staff members of the Resources Department, Ducks Unlimited and the Museum. Speakers are arranged in advance and motion pictures shown. Topics illustrated are designed for the correct use of fire-arms, personal conduct when out hunting and fishing, conservation practises and natural history.

The barrels were prepared by the boys under supervision at the Museum, and installed on the north-east of'Last Mountain Lake on a Sunday in March. All of the above mentioned organizations participated on the establishing of these fifty barrels on this occasion. We look forward to the results and hope they will be encouraging.

Regulations covering hunting and fishing are designed to allow harvesting of these crops and not deplete the supply.

Our sportsmen have too little contact with the needs and basic factors that contribute to the welfare of our game. Projects such as the Goldeneye Duck nest projects encourage better understanding and appreciation of the great privilege we enjoy in that of hunting and fishing in Canada. 


\section{CONSERVATION IN ACTION}

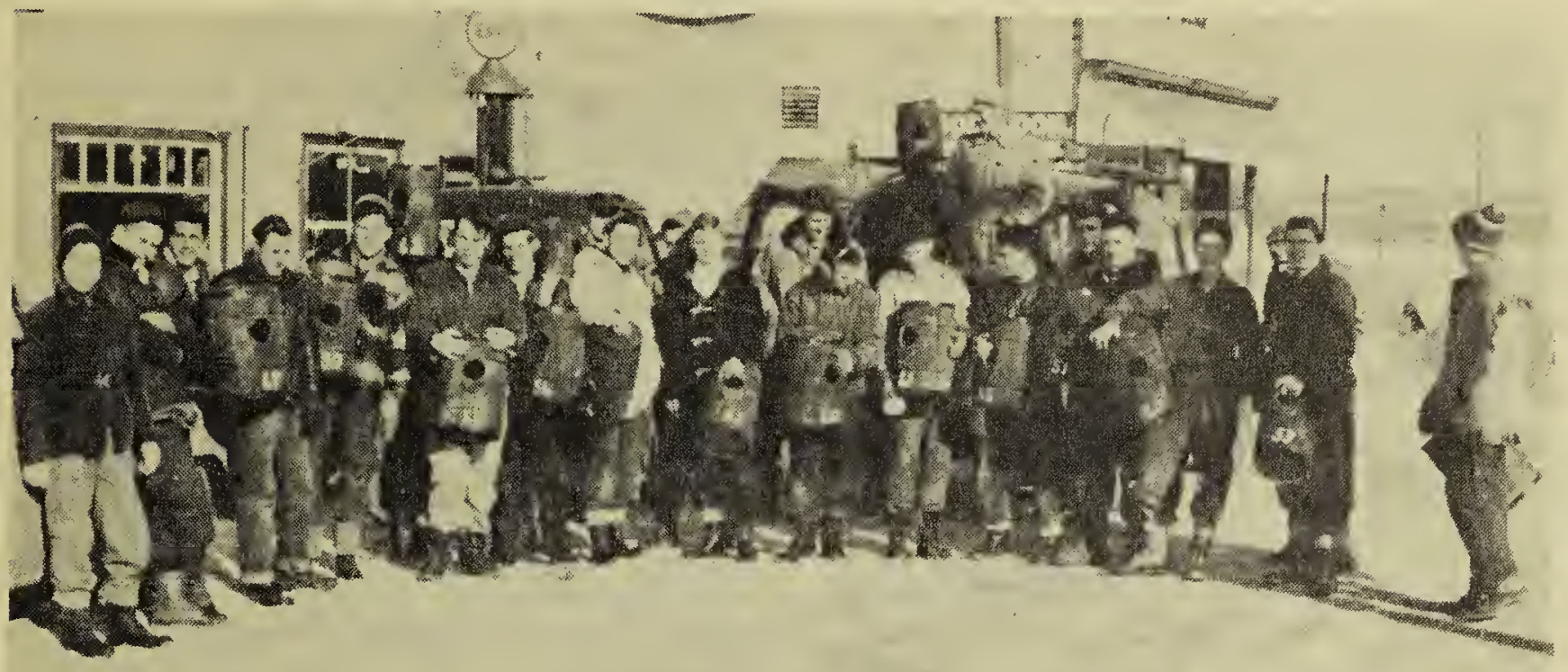

Wildlife Conservation League, Regina Beach, March 14, 1954

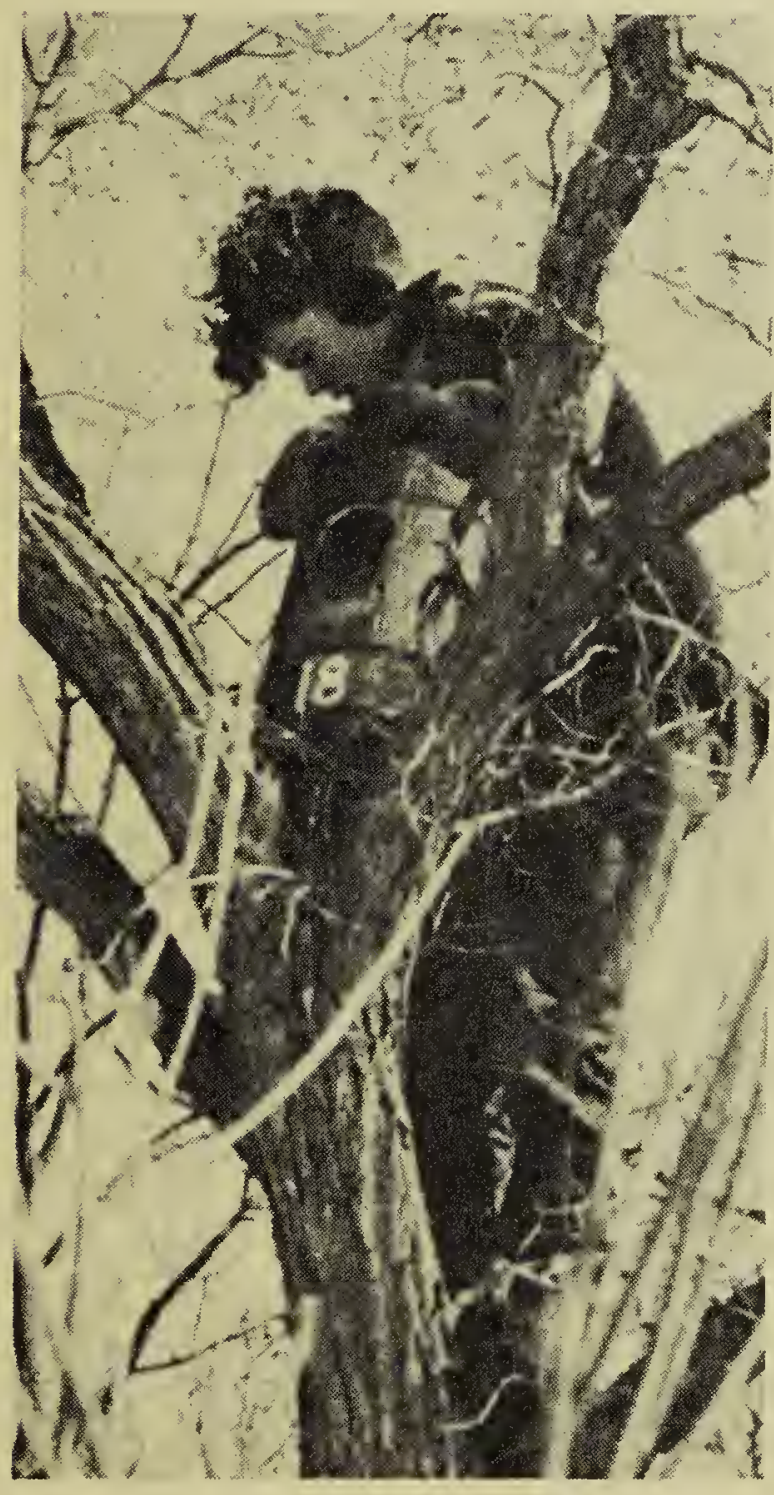

- Photo by Fred Bard

Placing nest kegs for Golden-eye Ducks
A Similar

Yorkton Project

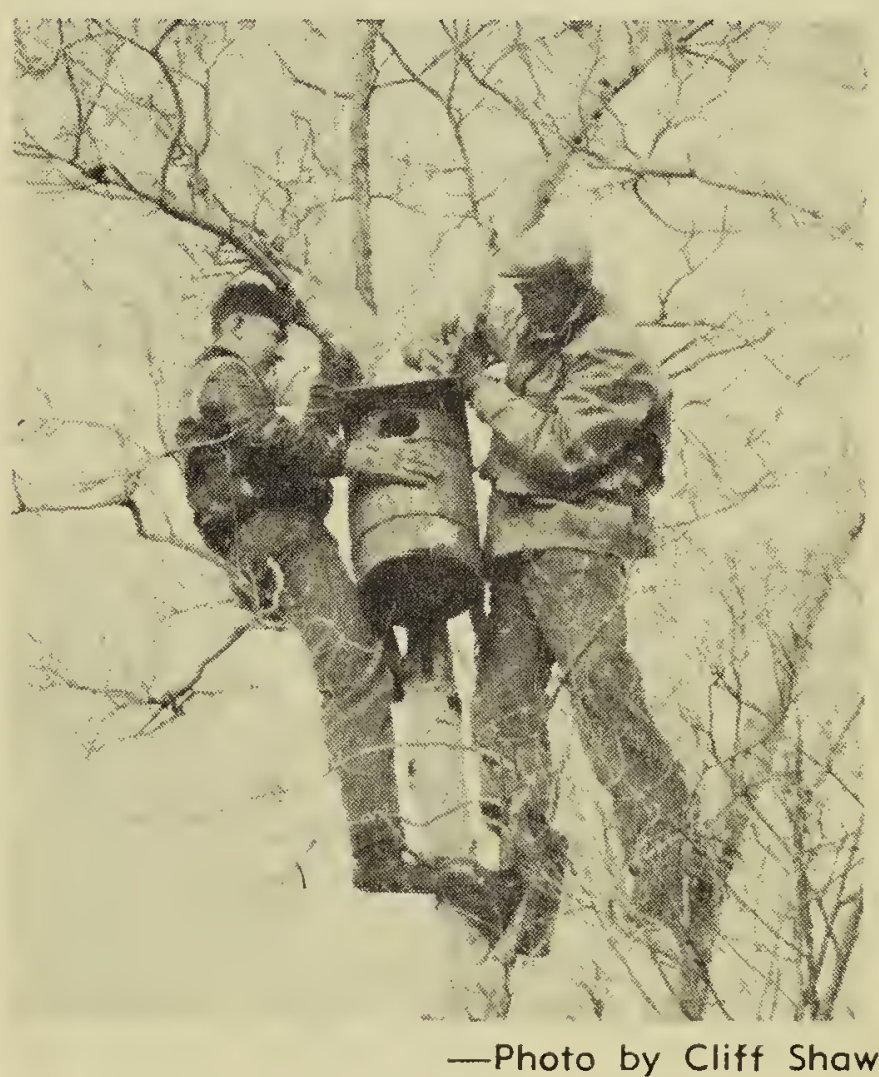

Photo of Wayne Bjorgan and friend putting up a Goldeneye nesting box at York Lake, within a hundred yards of a flock of Goldeneyes sitting on the water. We hope a pair will stay and use it. Dr. Suart Houston made 13 such boxes from nail kegs for use near Yorkton. They are placed about twenty feet above ground. Fred Bard and his Regina boys' conservation group have a similar project on a much larger scale. 